\title{
Responses of Nitrifiers' characteristics to Filling Ratio in IFAS Systems
}

\author{
Liuchao $\mathrm{Hu}^{\mathrm{a}}$, Yue Wen ${ }^{\mathrm{b}, ~}{ }^{*}$ and Qi Zhou ${ }^{\mathrm{c}}$ \\ College of Environmental Science and Engineering, Tongji University \\ Shanghai, China \\ ahu_liuchao@qq.com, ${ }^{b}$ weny@tongji.edu.cn (*corresponding author), ${ }^{c}$ zhouqi@tongji.edu.cn
}

\begin{abstract}
The concentrations of $\mathrm{NH}_{4}^{+}-\mathrm{N}, \mathrm{NO}_{2}^{-}-\mathrm{N}$ and $\mathrm{NO}_{3}^{-}-\mathrm{N}$ were measured in batch experiments to study nitrification kinetics in IFAS system with different FR at $0 \%-50 \%$. The results showed that both of $\mathrm{NH}_{4}{ }^{+}-\mathrm{N}$ oxidation rate $\left(R_{\mathrm{NH}_{4}^{+}-N}\right)$ and $\mathrm{NO}_{3}^{-}-\mathrm{N}$ production rate $\left(R_{N_{3}^{-}-N}\right)$ increased with $\mathrm{FR}$, which respectively increased from 6.3 to $16.9 \mathrm{mgNH}_{4}{ }^{+}-\mathrm{N} \cdot \mathrm{L}^{-}$ ${ }^{1} \cdot h^{-1}$ and 0.8 to $13.6 \mathrm{mgNO}_{3}-\mathrm{N} \cdot \mathrm{L}^{-1} \cdot \mathrm{h}^{-1}$. While the highest accumulation concentration of $\mathrm{NO}_{2}^{-}-\mathrm{N}$ fell from 51.8 to 9.0 $\mathrm{mg} \cdot \mathrm{L}^{-1}$. That was, higher $\mathrm{FR}$ instead went against to partial nitrification. Quantitative polymerase chain reaction (q-PCR) analysis revealed that increased $F R$ caused an acceleration of the nitrifiers, which correlated linearly with the nitrification rate. Furthermore, the amount of nitrifiers per unit area in biofilm reached maximum at $F R=30 \%$, and it was also the demarcation point when nitrifiers in biofilm outnumbered that in suspended sludge. Cumulative effect of nitrite occurred in the end of reaction when FR was less than $30 \%$.
\end{abstract}

Keywords-IFAS; filling ratio; nitrification performance; $A O B ; N O B$

\section{INTRODUCTION}

In China, the conventional activated sludge (CAS) process is often used to remove $\mathrm{COD}$ and $\mathrm{NH}_{4}{ }^{+}-\mathrm{N}$ in wastewater. However, this process presents some shortcomings when exposed to high hydraulic and organic loadings [1]. As the increasingly stringent emission standards of nitrogen, it's of great importance to upgrade the traditional nitrification tank. Integrated fixed-film activated sludge (IFAS) process is a good choice. By adding suspended carriers in the activated sludge, IFAS process cultivate two different biomasses, making sludge concentration be 5-10 times as much as that in CAS [2]. In addition, carriers provide adhesive environment for nitrifiers whose growth rates are relatively low, while the presence of suspended sludge creates conditions for heterotrophic bacteria. As a consequence, IFAS process can achieve high removal rate of both $\mathrm{COD}$ and $\mathrm{NH}_{4}{ }^{+}-\mathrm{N}$ even under low temperature $[1,3]$.

Filling ratio (FR) is one of the most important parameters in IFAS process. Some studies have been carried out on systems adding suspended carriers at different FR to investigate process efficiencies in recent years [4-6]. Whereas the available information remains limited pertaining to the characterization of nitrifying bacteria both in suspended sludge and biofilm as a response to the FR, which make it difficult to put IFAS process into practical applications.

In this study, six IFAS reactors were therefore constructed at different FR from $0 \%$ to $50 \%$. Batch experiments and quantitative polymerase chain reaction (qPCR) were conducted when reactors ran stably to study nitrification kinetics and population structure of the nitrifiers. The aims of the research were to investigate: $i$. the effect of FR on nitrification performance in IFAS process; ii. functional relationships between nitrification rates and nitrifying bacteria; iii. variant roles of nitrifiers in suspended sludge and biofilm on system efficiency; iv. why nitrifiers did different responses with FR increasing.

\section{MATERIALS AND METHODS}

\section{A. Experimental systems}

Six laboratory-scale sequencing batch IFAS reactors were constructed with a working volume of $15.0 \mathrm{~L}$ $(\Phi 190 \mathrm{~mm} \times 540 \mathrm{~mm})$. Each reactor was equipped with peristaltic pumps (BT100-2J, Longer Pump Co., China), air pumps (IPX4 ACO-9610, Hailea Group Co., China) and a aeration disc (V-30, Hailea Group Co., China), which was fixed at the bottom of the reactor to provide sufficient dissolved oxygen (DO) and fluidize the carriers. Cylinder suspended plastic bio-carriers (SPR-1) were used in this experiment as attached materials for microbes that had a density of $0.96 \mathrm{~g} \cdot \mathrm{cm}^{-3}$ and the effective specific surface area of $500 \mathrm{~m}^{2} \cdot \mathrm{m}^{-3}$.

\section{B. Batch experiments}

Batch experiments were performed when systems ran stably. The concentrations of $\mathrm{NH}_{4}^{+}-\mathrm{N}, \mathrm{TP}$ and trace elements contained in raw water was the same as that in sequencing batch tests, while COD wasn't added in order to reduce the influence of heterotrophs on the nitrifiers. Liquid samples were taken at regular intervals and immediately filtered through Millipore filter units $(0.45 \mu \mathrm{m}$ pore size) to analyze $\mathrm{NH}_{4}{ }^{-}-\mathrm{N}, \mathrm{NO}_{2}^{-}-\mathrm{N}$ and $\mathrm{NO}_{3}{ }^{-}-\mathrm{N}$.

\section{Quantitative polymerase chain reaction ( $q-P C R)$}

DNA was extracted from biofilms sampled from six reactors and amplified according to primer features of nitrifiers listed in table. I[7]. Reaction mixtures $(50 \mu l$ final volume) contained $1 \times$ Gold PCR buffer $(150 \mathrm{mM}$ Tris- $\mathrm{HCl}$, $\mathrm{pH}=8.0,500 \mathrm{mM} \mathrm{KCl}), \quad 1.5 \mathrm{mM} \quad \mathrm{MgCl}_{2}, \quad 5 \%$ dimethylsulfoxide, $200 \mu \mathrm{M}$ of dNTPs, $20 \mathrm{pM}$ of each primer, $1 \mathrm{U}$ of AmpliTaq Gold polymerase and $100 \mu \mathrm{g}$ bovine serum albumine [6]. The temperature profile for PCR reaction was as follows [8]: initial denaturation at $95^{\circ} \mathrm{C}$ for $3 \mathrm{~min} ; 40$ cycles of denaturation at $95^{\circ} \mathrm{C}$ for $15 \mathrm{~s}$, annealing at $56^{\circ} \mathrm{C}$ for $30 \mathrm{~s}$, extension at $72^{\circ} \mathrm{C}$ for $30 \mathrm{~s}$, the second extension at $80^{\circ} \mathrm{C}$ for $30 \mathrm{~s}$; and final reparation 
extension at $72^{\circ} \mathrm{C}$ for $7 \mathrm{~min}$. The final PCR products were cleaned and concentrated using Amicon Ultra- $0.5 \mathrm{ml}$ Centrifugal Filters.

TABLE I. THE PRIMER SEQUENCES OF AOB, AOA AND NOB

\begin{tabular}{|c|c|c|}
\hline \multicolumn{2}{|c|}{ Species } & Primer Sequence \\
\hline \multicolumn{2}{|c|}{ AOB } & $\begin{array}{c}\text { amoA-1F(5'-GGGGGTTTCTACTGGTGGT-3') } \\
\text { amoA-2R(5'-CCCCTCKGSAAAGCCTTCTTC-3') }\end{array}$ \\
\hline \multicolumn{2}{|c|}{ AOA } & $\begin{array}{l}\text { Arch-amoAF(5'-STAATGGTCTGGCTTAGACG-3') } \\
\text { Arch-amoAR(5'-GCGGCCATCCATCTGTATGT-3') }\end{array}$ \\
\hline \multirow{2}{*}{ NOB } & Nitrospira & $\begin{array}{c}\text { EUB338f(5'-ACTCCTACGGGAGGCAGC-3') } \\
\text { Ntspa0685M(5'-CGGGAATTCCGCGCTC-3') }\end{array}$ \\
\cline { 2 - 3 } & Nitrobacter & $\begin{array}{c}\text { EUB338f(5'-ACTCCTACGGGAGGCAGC-3') } \\
\text { NIT3(5'-CCTGTGCTCCATGCTCCG-3') }\end{array}$ \\
\hline
\end{tabular}

\section{RESULTS AND DISCUSSION}

\section{A. Nitrification performance in IFAS systems}

The batch tests were operated to assess the nitrification performance in IFAS systems (fig. 1). Calculated sum values of $\mathrm{NO}_{2}^{-}-\mathrm{N}$ and $\mathrm{NO}_{3}^{-}-\mathrm{N}$ concentrations were almost equal to the oxidized $\mathrm{NH}_{4}{ }^{+}-\mathrm{N}$ concentration, demonstrating that almost no denitrification occurred in all reactors. It was mainly due to the high DO concentration (DO $\geq 2.0 \mathrm{mg} \cdot \mathrm{L}^{-1}$ ) controlled throughout the experiment.

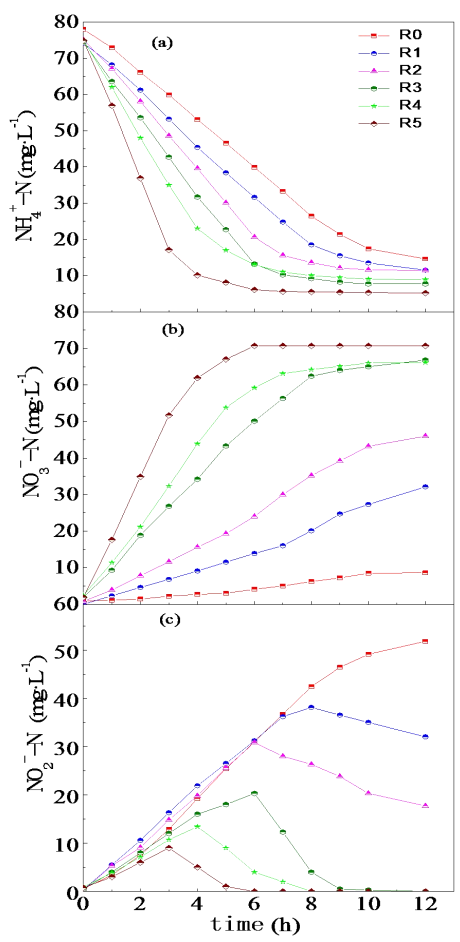

Figure 1. Variations in $\mathrm{NH}_{4}^{+}-\mathrm{N}, \mathrm{NO}_{3}^{-}-\mathrm{N}$ and $\mathrm{NO}_{2}^{-}-\mathrm{N}$ concentration during one typical batch test in six IFAS systems: (a) reduction of $\mathrm{NH}_{4}^{+}$$\mathrm{N}$; (b) production of $\mathrm{NO}_{3}^{-}-\mathrm{N}$; (c) accumulation of $\mathrm{NO}_{2}^{-}-\mathrm{N}$.

It was not hard to find that both of $R_{\mathrm{NH}_{4}^{+}-\mathrm{N}}$ and $R_{N 0_{3}^{-N}}$ markedly increased with FR, which respectively increased from 6.3 to $16.9 \mathrm{mgNH}_{4}^{+}-\mathrm{N} \cdot \mathrm{L}^{-1} \cdot \mathrm{h}^{-1}$ and 0.8 to $13.6 \mathrm{mgNO}_{3}^{-}-\mathrm{N} \cdot \mathrm{L}^{-1} \cdot \mathrm{h}^{-1}$. Such variations indicated that higher FR could improve the nitrification performance, especially do more benefit to $R_{N O_{3}^{-} N}$. The highest accumulation concentration of $\mathrm{NO}_{2}{ }^{-}-\mathrm{N}$ exhibited negative correlation with FR as indicated by correlation coefficient $\mathrm{R}^{2}$ of 0.975 (fig. 3a), which further confirmed that increased FR was adverse to nitrite accumulation. Also, IFAS system in this experiment could accomplish exhaustive nitration once $\mathrm{FR} \geq 30 \%$.

\section{B. Functional relationship between nitrification rate and nitrifying bacteria}

The concentrations of AOA, AOB and NOB (Nitrobacter and Nitrospira) were analyzed using q-PCR to reveal nitrifiers' responses to FR. As shown in the fig. 2, AOB was the main undertaker in ammonia oxidation process, yet AOA concentration was practically negligible. The linear correlation analysis (fig. $3 b, 3 c$ and $3 d$ ) indicated that $\mathrm{AOB}$ and $\mathrm{NOB}$ were well correlated with $R_{N_{4}^{+}-N}$ and $R_{N O_{3}^{-}-N}\left(\mathrm{R}^{2}=0.889\right.$ and 0.959$)$, respectively, and $\mathrm{AOB} / \mathrm{NOB}$ exhibited good correlations with the highest accumulation concentration of $\mathrm{NO}_{2}^{-}-\mathrm{N}\left(\mathrm{R}^{2}=0.902\right)$. Therefore, the varying numbers of $\mathrm{AOB}, \mathrm{NOB}$ and their ratio as a result of FR were valid for estimating different nitrification performance.
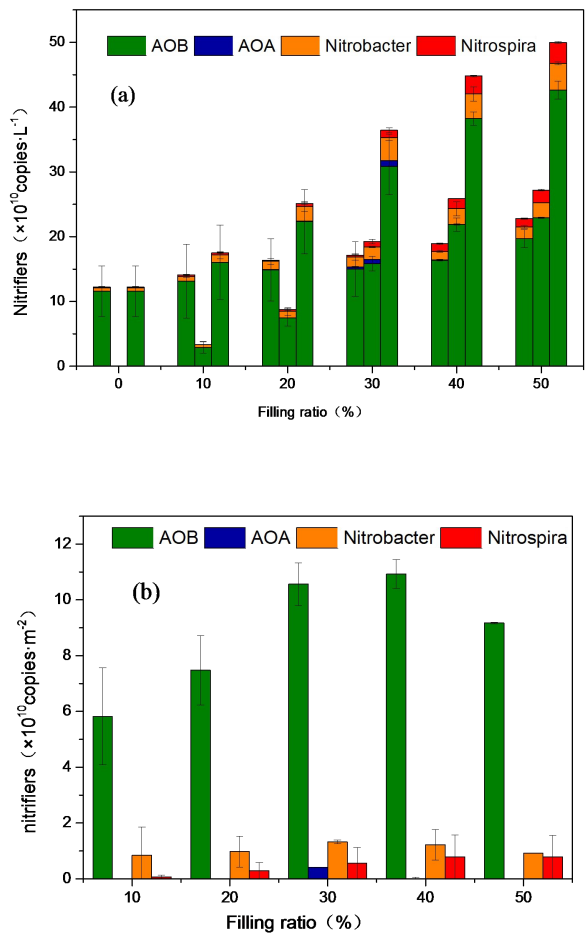

Figure 2. (a) Nitrifiers' concentration in suspended sludge, biofilm and IFAS systems at FR $=0 \%-50 \%$; (b) nitrifiers' concentration per unit area in biofilm at $\mathrm{FR}=0 \%-50 \%$.

\section{Responses of nitrifiers' characteristics to FR}

\section{1) Activities of $A O B$ and $A O A$}

The linear correlations of nitrifiers' concentration and FR were listed in fig. 4. Compared with AOB, AOA occupied little amount in six reactors. The reason was that DO was always controlled above $2 \mathrm{mg} \cdot \mathrm{L}^{-1}$ to fluidize carriers and inhibit denitrification, which seemed adverse to growth of AOA [9]. However, the amount of AOA 
raised significantly at $\mathrm{FR}=30 \%$, accounting for $3.69 \%$ of ammonia oxidizing microbes. It was hypothesized that DO and substrate concentration gradient caused by proper thickness of biofilm played a part [10], in other words, it was favorable to cultivate AOA at FR $=30 \%$.

The amount of AOB was always over $80 \%$ of nitrifying bacteria, and was positively linearly correlated with FR both in suspended sludge and biofilm $\left(\mathrm{R}^{2}=0.932\right.$, 0.955, fig. 4a). Notably, unlike upward trend at other FR, the amount of AOB per unit area in biofilm declined contrary at $\mathrm{FR}=50 \%$. This was probably related to carriers' fluidization. Gjaltema et al [11] demonstrated that although the total surface area of carriers increased with FR, shear stresses on biofilm became greater and detachment enhanced when FR was more than 50\%. It conformed to the phenomenon in this study that nitrifiers per unit area in biofilm declined at $\mathrm{FR}=50 \%$. Moreover,
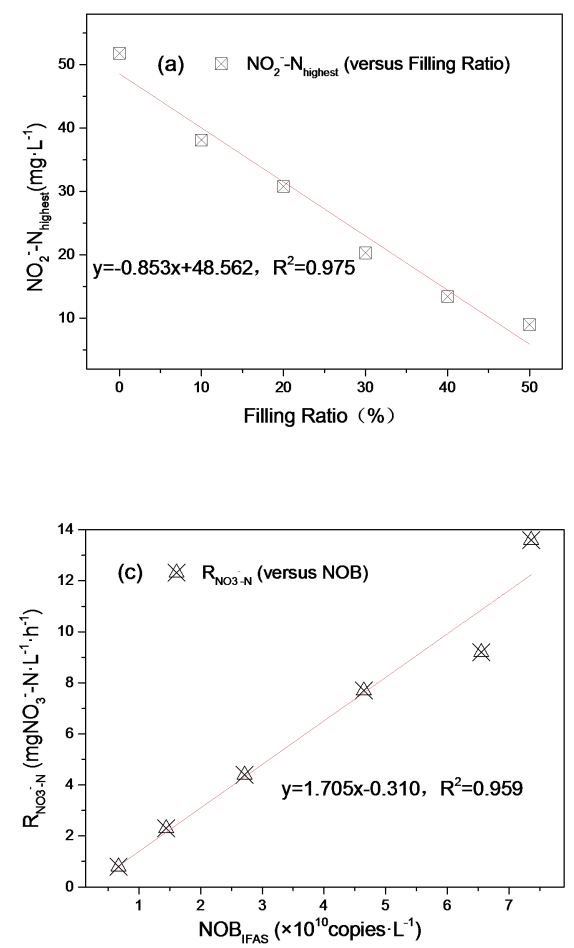

the amount of AOB in suspended sludge was very close to that in biofilm at $\mathrm{FR}=30 \%$, above which $\mathrm{AOB}$ in biofilm would outnumbered. That was, the sludge dominating $R_{N_{4}^{+}-N}$ changed from suspended state to biofilm with FR increasing. The concentrations of AOA, AOB and NOB (Nitrobacter and Nitrospira) were analyzed using q-PCR to reveal nitrifiers' responses to FR. As shown in the fig. 2, $\mathrm{AOB}$ was the main undertaker in ammonia oxidation process, yet AOA concentration was practically negligible. The linear correlation analysis (fig. $3 \mathrm{~b}, 3 \mathrm{c}$ and $3 \mathrm{~d}$ ) indicated that $\mathrm{AOB}$ and $\mathrm{NOB}$ were well correlated with $R_{N H_{4}^{+}-N}$ and $R_{N O_{3}^{-}-N}\left(\mathrm{R}^{2}=0.889\right.$ and 0.959$)$, respectively, and $\mathrm{AOB} / \mathrm{NOB}$ exhibited good correlations with the highest accumulation concentration of $\mathrm{NO}_{2}^{-}-\mathrm{N}\left(\mathrm{R}^{2}=0.902\right)$. Therefore, the varying numbers of $\mathrm{AOB}, \mathrm{NOB}$ and their ratio as a result of FR were valid for estimating different nitrification performance.
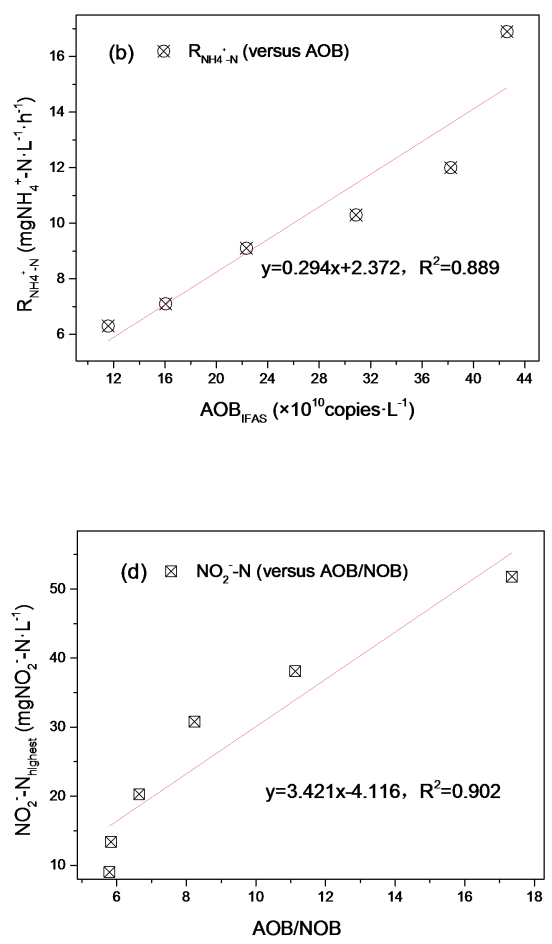

Figure 3. (a) Relationship between $\mathrm{NO}_{2}^{-}-\mathrm{N}_{\text {highest }}$ and FR; (b) relationship between $R_{N H_{4}^{+}-N}$ and $\mathrm{AOB}_{\mathrm{IFAS}}$; (c) relationship between $R_{N O_{3}^{-}-N}$ and $\mathrm{NOB}_{\text {IFAS }}$; (d) relationship between $\mathrm{NO}_{2}-\mathrm{N}_{\text {highest }}$ and $\mathrm{AOB} / \mathrm{NOB}$.

\section{2) Activities of $N O B$}

The quantity of Nitrospira in biofilm was well positively correlated with FR $\left(\mathrm{R}^{2}=0.979\right.$, fig. $\left.4 \mathrm{~d}\right)$, whereas Nitrobacter was trending downward when FR exceeded $40 \%$, illustrating that higher FR was more conducive to culture Nitrospira. Schramm et al [12] determined the population structure of nitrifying bacteria by combined use of microsensors and fluorescence in situ hybridization (FISH), and probed Nitrospira in the microaerobic zone of biofilm, i.e. between 150 and $300 \mu \mathrm{m}$ away from the membrane, even out-competing Nitrobacter. Authors then tested concentrations of $\mathrm{DO}, \mathrm{NO}_{3}^{-}-\mathrm{N}, \mathrm{NO}_{2}^{-}-\mathrm{N}$ in the biofilm, and implied that it was the affinity for $\mathrm{DO}$, not $\mathrm{NO}_{2}{ }^{-}-\mathrm{N}$ that played a selective role. Because the concentrations of $\mathrm{NO}_{2}{ }^{-}-\mathrm{N}$ and $\mathrm{DO}$ in this range were respectively about $400-500 \mu \mathrm{M}$ and $0-15 \mu \mathrm{M}$, according to the $\mathrm{K}_{\mathrm{m}}\left(\mathrm{NO}_{2}^{-}-\mathrm{N}, 60-600 \mu \mathrm{M}\right)$ and $\mathrm{K}_{\mathrm{m}}(\mathrm{DO}, 62-256 \mu \mathrm{M})$ of Nitrobacter, a competitive advantage for Nitrospira on the basis of oxygen affinity would prevail over. In this study, Nevertheless, DO always maintained about $2-4 \mathrm{mg} \cdot \mathrm{L}^{-1}$ in bulk solution, while the highest accumulation concentration of $\mathrm{NO}_{2}^{-}-\mathrm{N}$ declined with FR from 38.1 to 9.0 $\mathrm{mg} \cdot \mathrm{L}^{-1}$, so it was more likely the concentration gradient of $\mathrm{NO}_{2}^{-}-\mathrm{N}$ in biofilm at various $\mathrm{FR}$ that made for such changes. Besides, the change trends of Nitrobacter and Nitrospira in suspended sludge was in accordance with that in biofilm. Due to the relatively low growth rate of NOB, we speculated that this part increment was mainly caused by the shedding of biofilm. 

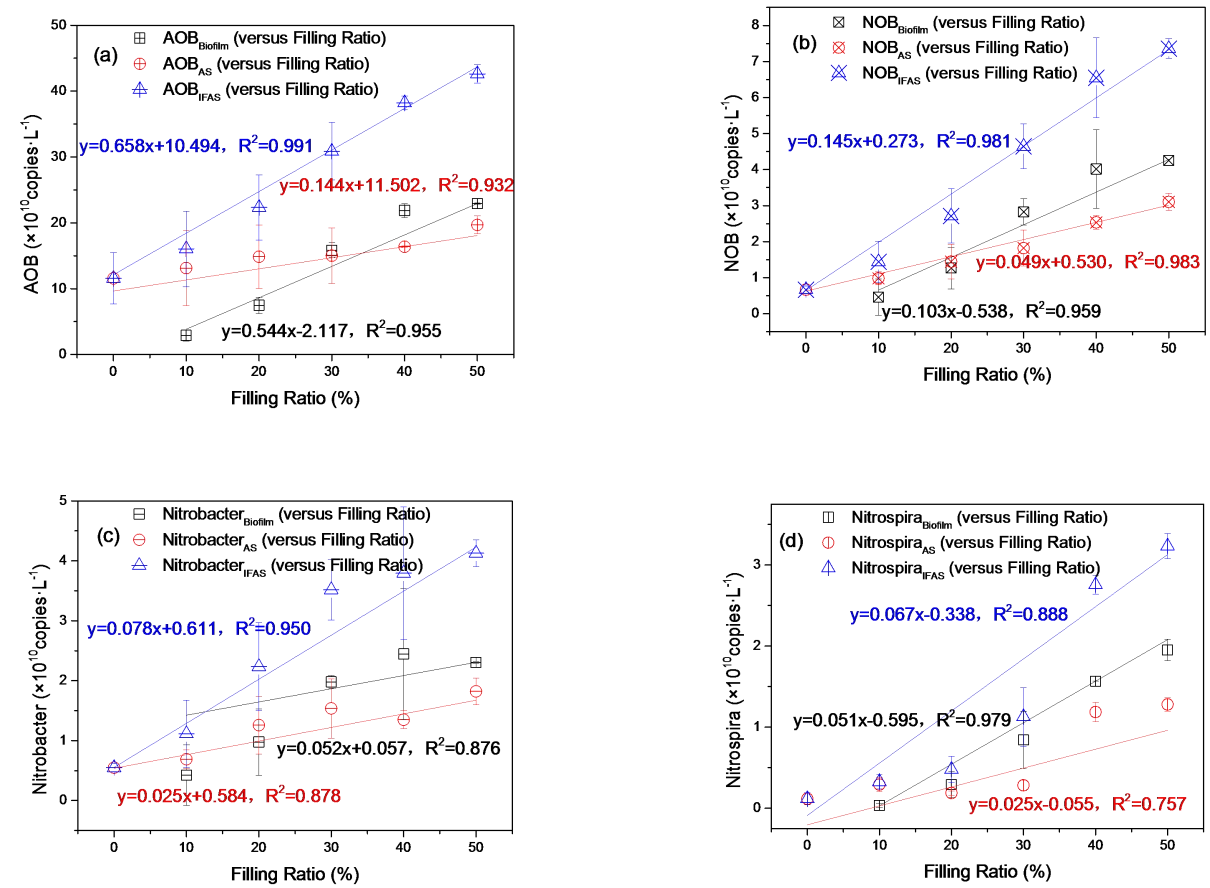

Figure 4. Correlation analysis between nitrifiers' concentration and FR in suspended sludge, biofilm and IFAS systems: (a) relationships between AOB and FR; (b) relationships between NOB and FR; (c) relationships between Nitrobacter and FR; (d) relationships between Nitrospira and FR.

\section{CONCLUSIONS}

The results demonstrate that: i. IFAS process is an efficient biological treatment to remove $\mathrm{NH}_{4}{ }^{+}-\mathrm{N}$, and nitrification performance improved with FR increasing from $10 \%$ to $50 \%$. Higher FR did more increment to $R_{\mathrm{NO}_{2}^{-}-\mathrm{N}}$ than $R_{\mathrm{NH}_{4}^{+}-\mathrm{N}}$, resulting in inferior performance at partial nitrification; ii. linear analysis showed that increasement of $\mathrm{AOB}$ and $\mathrm{NOB}$ is the fundamental reasons to improve $R_{N H_{4}^{+}-N}$ and $R_{N O_{3}^{-}-N}$, while accumulation concentration of $\mathrm{NO}_{2}^{-}-\mathrm{N}$ mainly depended on $\mathrm{AOB} / \mathrm{NOB}$; iii. the amount of nitrifiers per unit area in biofilm reached maximum at $\mathrm{FR}=30 \%$, and it was also the demarcation point when nitrifiers in biofilm outnumbered that in suspended sludge; iv. the change of total effective surface area and substrate concentration gradient in biofilm caused by FR was the main reason to influence nitrifiers' concentration.

\section{REFERENCES}

[1] D. Di Trapani, M. Christensson, M. Torregrossa, G. Viviani and H. Ødegaard, "Performance of a hybrid activated sludge/biofilm process for wastewater treatment in a cold climate region: Influence of operating conditions," Biochemical Engineering Journal, Vol. 77, 2013, pp. 214-219.

[2] C. L. A. Maas, W. J. Parker and R. L. Legge, "Detachment of Solids and Nitrifiers in Integrated, Fixed-Film Activated Sludge Systems," Water Environment Research, Vol. 80, No. 12, 2008, pp. 2202-2208.

[3] T. Sriwiriyarat and C. W. Randall, "Evaluation of integrated fixed film activated sludge wastewater treatment processes at high mean cells residence time and low temperatures," Journal of Environmental Engineering-Asce, Vol. 131, No. 11, 2005, pp. 1550-1556.

[4] Q. Feng, Y. Wang, T. Wang, H. Zheng, L. Chu, C. Zhang, H. Chen, $\mathrm{X}$. Kong and X. H. Xing, "Effects of packing rates of cubic-shaped polyurethane foam carriers on the microbial community and the removal of organics and nitrogen in moving bed biofilm reactors," Bioresour Technol, Vol. 117, 2012, pp. 201-7.

[5] R.-C. Wang, X.-H. Wen and Y. Qian, "Influence of carrie concentration on the performance and microbial characteristics of a suspended carrier biofilm reactor," Process Biochemistry, Vol. 40, No. 9, 2005, pp. 2992-3001.

[6] K. Calderon, J. Martin-Pascual, J. M. Poyatos, B. Rodelas, A Gonzalez-Martinez and J. Gonzalez-Lopez, "Comparative analysis of the bacterial diversity in a lab-scale moving bed biofilm reactor (MBBR) applied to treat urban wastewater under different operational conditions," Bioresour Technol, Vol. 121, 2012, pp. 119-26.

[7] Y.-J. Wu, L.-M. Whang, M.-Y. Chang, T. Fukushima, Y.-C. Lee S.-S. Cheng, S.-F. Hsu, C.-H. Chang, W. Shen, C.-Y. Yang, R. Fu and T.-Y. Tsai, "Impact of food to microorganism (F/M) ratio and colloidal chemical oxygen demand on nitrification performance of a full-scale membrane bioreactor treating thin film transistor liquid crystal display wastewater," Bioresour Technol, Vol. 141, 2013, pp. 35-40.

[8] F. Persson, R. Sultana, M. Suarez, M. Hermansson, E. Plaza and B. M. Wilen, "Structure and composition of biofilm communities in a moving bed biofilm reactor for nitritation-anammox at low temperatures," Bioresour Technol, Vol. 154, 2014, pp. 267-273.

[9] H.-D. Park, G. F. Wells, H. Bae, C. S. Criddle and C. A. Francis, "Occurrence of ammonia-oxidizing archaea in wastewater treatment plant bioreactors," Applied and Environmental Microbiology, Vol. 72, No. 8, 2006, pp. 5643-5647.

[10] S. Leininger, T. Urich, M. Schloter, L. Schwark, J. Qi, G. W. Nicol, J. I. Prosser, S. C. Schuster and C. Schleper, "Archaea predominate among ammonia-oxidizing prokaryotes in soils," Nature, Vol. 442, No. 7104, 2006, pp. 806-809.

[11] A. Gjaltema, L. Tijhuis, M. C. M. Vanloosdrecht and J. J. Heijnen, "Detachment of biomass from suspended nongrowing spherical biofilms in airlift reactros," Biotechnology and Bioengineering, Vol. 46, No. 3, 1995, pp. 258-269.

[12] A. Schramm, D. De Beer, A. Gieseke and R. Amann, "Microenvironments and distribution of nitrifying bacteria in a membrane-bound biofilm," Environmental Microbiology, Vol. 2, No. 6, 2000, pp. 680-686. 